\title{
Circuito produtivo da Agência Pública e as possibilidades para a expansão das liberdades
}

\section{Productive circuit of the Agência Pública and the possibilities for the expansion of freedoms}

\author{
Ângela Cristina Trevisan Felippi \\ Universidade de Santa Cruz do Sul \\ <angelafe@unisc.br>
}

\author{
Vanessa Costa de Oliveira \\ Universidade de Santa Cruz do Sul \\ $<$ nessa.costa.oliveira@gmail.com>
}

\section{Como citar este artigo (How to cite this article):}

FELIPPI , Ângela Cristina Trevisan; OLIVEIRA, Vanessa Costa de. Circuito produtivo da Agência Pública e as possibilidades para a expansão das liberdades. Revista Famecos, Porto Alegre, v. 25, n. 2, p. 1-21, maio, junho, julho e agosto de 2018: ID27593. DOI: http://dx.doi.org/10.15448/1980-3729.2018.2.27593.

\section{RESUMO}

Experiências de produção jornalísticas alternativas ao modelo hegemônico são registradas há pelo menos um século no Brasil. Entre os representantes contemporâneos dessa prática jornalística está a Agência de Reportagens Investigativas Pública. O artigo busca compreender a proposta de produção da Agência Pública e sua possível autonomia na produção de conteúdos, examinando a possibilidade do conteúdo veiculado pela agência potencialmente contribuir para expansão das liberdades individuais, propostas por Amartya Sen (2010), capazes de levar ao desenvolvimento da sociedade. Utiliza-se como protocolo teórico-metodológico o circuito da cultura, de Richard Johnson (2010), com categorias pré-definidas. Faz-se uso da entrevista e da análise documental. A pesquisa conclui que a estratégia produtiva da Pública, de operar com autonomia em relação à publicidade e sem fins lucrativos, com distribuição gratuita do conteúdo e tendo como foco a exposição das fragilidades da realidade social brasileira, materializada numa reportagem analisada, contribui para a expansão das liberdades.

Palavras-chave: Agência de reportagens. Circuito produtivo. Desenvolvimento como liberdade.

\begin{abstract}
Experiences of journalistic production alternatives to the hegemonic model have been recorded for at least a century in Brazil. Among the contemporary representatives of this journalistic practice is the Agency of Investigative Reporting Public. The article seeks to understand the proposal of production of the Agency Public and its possible autonomy in the production of contents, examining the possibility of the content conveyed by the agency potentially contribute to the expansion of individual freedoms, proposed by Amartya Sen (2010), able to lead to the development of society. Circuit of culture, by Richard Johnson (2010), with predefined categories, is used as the theoretical-methodological protocol. It's used interview and documentary analysis. The research concludes that the productive strategy of Public, to operate with autonomy in relation to publicity and non-profit, with free distribution of the content and having as focus the exposition of the fragilities of the Brazilian social reality, materialized in an analyzed article, contributes to the expansion of freedoms.
\end{abstract}

Keywords: News Agency. Productive circuit. Development as freedom. 


\section{Introdução}

Ao largo dos modelos de produção jornalísticos hegemônicos, ao menoso último século registra distintas experiências alternativas de produção, circulação ou recepção jornalística no Brasil. Uma delas, emergente na atual década, é o modelo exemplificado com a Agência Pública. A agência de reportagens se autodenomina independente, com um jornalismo que se propõe de interesse público e autônomo em relação à publicidade, sustentado pelo financiamento ou crowdfunding, num negócio sem fins lucrativos. Criada em 2011, com sede em São Paulo, a Pública desde então produz reportagens com foco nas questões ambientais e do mundo do trabalho e as distribui gratuitamente. As reportagens em texto e imagem são publicadas no site da agência e compartilhadas em redes sociais, ficando à disposição dos leitores e da mídia em geral, os chamados republicadores.

Mais do que o interesse pelo modelo de negócio, este artigo se debruça sobre a proposta de operação com independência da Agência Pública e a possível autonomia para a produção de conteúdos que isso lhe garante, examinando a relação entre este modelo e as possibilidades que o mesmo abre para que a informação permita a expansão das liberdades individuais. A concepção da expansão das liberdades vem do economista Amartya Sen, um dos idealizadores do Índice de Desenvolvimento Humano (IDH), que pensa o desenvolvimento relacionado à garantia dessas liberdades.

Para tal, compreende-se o jornalismo como fenômeno cultural, sujeito a um processo produtivo, composto de distintos momentos interligados e relacionados, estudado nesta pesquisa a partir do protocolo metodológico do circuito da cultura de Richard Johnson (2010). O circuito traz categorias prédefinidas, quais sejam: produção, textos, relações sociais e leituras. $O$ estudo se detém mais particularmente nas três primeiras, inclusive propondo o acréscimo de uma nova, as condições de produção, e tem o propósito de compreender se o jornalismo praticado pela Pública tem condições de possibilitar a expansão das liberdades individuais e, desta forma, ser um catalizador para o desenvolvimento. Trata-se de um estudo realizado num programa de pós-graduação na área de Desenvolvimento Regional (PURDE-CAPES), portanto seu fim maior é estabelecer relações possíveis entre a comunicação e o desenvolvimento.

\section{Comunicação e Desenvolvimento: aproximações}

As teorias do desenvolvimento nascem no século XX, na esteira da expansão do capital industrial pelo planeta, associadas à concepção de crescimento econômico. Suas origens vêm de Adam Smith, economista do clássico A riqueza das nações, de 1776, que compreendia o crescimento de 
determinado lugar pela acumulação de capital (Smith, 1983). Outros clássicos, como Ricardo e Malthus, pensaram o crescimento por meio da ampliação do comércio exterior e na ampliação da demanda efetiva, respectivamente (Hunt e Sherman, 2010). O primeiro a utilizar o termo desenvolvimento no intuito de diferenciá-lo de crescimento, foi Joseph Schumpeter, já no século XX, ainda sob uma óptica economicista.

É no pós-guerra que surgem as primeiras pesquisas que associam a comunicação ao desenvolvimento. A partir de uma perspectiva técnica e instrumental da comunicação de massa, estabeleceu-se uma relação causal entre a existência de meios de comunicação de massa modernos e a alta renda per capita, assim como entre esta e as taxas de urbanismo e de industrialização dos países, como indicadores do desenvolvimento (Lerner; Schramm, 1973). Para os autores, através dos meios de comunicação de massa se faria ensinar "aos povos das regiões em desenvolvimento" o que querer e o como ter, questões inerentes ao processo de consumismo, um dos elementos que move o capitalismo (Lerner; Schramm, 1973, p.323).

Embasados nessa concepção, países da América Latina, África e Ásia, tiveram, por décadas, políticas de desenvolvimento de orientação dos países centrais, cujo uso da comunicação estava contido. A partir do modelo de difusão de inovações, elaborado por Everett Rogers, foram desenvolvidas técnicas, ferramentas e modos de fazer a comunicação para a intervenção social com vistas ao desenvolvimento. Por volta dos anos 80 , a comunicação para o desenvolvimento passou por duras críticas, inclusive pelo seu insucesso, relacionado à crise do modelo.

Cabe retomar as análises de Juan Diaz Bordenave, representante dos estudos críticos da comunicação desenvolvimentista latino-americana. No Seminário sobre Comunicação no Desenvolvimento Econômico, em 1964, promovido pela Associação Internacional Americana, marco para a exploração da área para o desenvolvimento, chamou a atenção para o caráter de dependência do modelo de desenvolvimento proposto, no qual à comunicação era destinado um papel central. "Nossa atenção centrou-se em descobrir como as pessoas utilizavam a comunicação em seu próprio interesse, ou em outras palavras, quais seriam as funções que a comunicação oferecia ao indivíduo" (Bordenave, 1974, p.6). A comunicação para o desenvolvimento tinha caráter persuasivo e pouco crítico.

No Brasil, Melo (1977, p.20) chegou a concordar com a premissa de que cabia à comunicação de massa acelerar o processo de "modernização das sociedades tradicionais" e que os pesquisadores deveriam se empenhar na busca de processos que pudessem indicar como realizar esta tarefa. Mas é importante 
notar que, nesse período, final da década de 1970, o autor já questionava esse modelo de desenvolvimento sem implicações de natureza sociocultural. Ele afirmou que estavam sendo negligenciados questionamentos como: "em que estrutura social as inovações (na agricultura) serão introduzidas? Quais os padrões culturais (crenças, valores, normas, interações, etc.) ali dominantes? Quais os centros de decisão sob os quais gravita a organização social? " (Melo, 1977, p.22).

Nessa perspectiva questionadora do modelo de desenvolvimento econômico, Furtado, já em 1974, afirmava que o modelo era um mito, baseado em, principalmente, três elementos: a) não pode ser generalizado no Brasil nos moldes dos países desenvolvidos; b) os recursos naturais e não renováveis constituem um obstáculo que deve ser respeitado e c) os problemas estruturais do Brasil, em que é privilegiado o consumo de poucos e ampliada a desigualdade social.

Acentuaram-se, também, as críticas em relação ao difusionismo. Paulo Freire, em Extensão ou Comunicação? (2011), escrito durante o seu exílio no Chile, publicado originalmente em 1969, faz críticas à prática da extensão, uma das principais formas de chegada das políticas governamentais de desenvolvimento, como um movimento de transmissão de mensagens a alguém que a recebe sem fazer as devidas reflexões. Em outras palavras, uma crítica ao tecnicismo. Na obra, Freire propõe a comunicação como um diálogo, no qual há troca de conhecimentos entre os interlocutores.

Bordenave chegou a formular um novo conceito para comunicação rural, área que concentrou seus estudos, associada até então ao difusionismo. Numa perspectiva dialógica, a comunicação para o desenvolvimento seria o "conjunto de fluxos de informação, de diálogo e de influência recíproca existente entre os componentes do setor rural e entre eles e os demais setores da nação afetados pelo funcionamento da agricultura, ou interessados no melhoramento da vida rural" (Bordenave, 1985, p. 7).

Com a crise do modelo, a comunicação para o desenvolvimento perdeu força no campo da pesquisa, seguiu enfraquecida, porém ativa enquanto prática em alguns órgãos de intervenção dos governos e da iniciativa privada e organizações da sociedade civil, com mescla de modelos de aplicação. Mais recentemente, as reflexões acadêmicas que dialogam com a prática especialmente dos movimentos sociais têm caminhado para aplicações possíveis dos princípios propostos por Bordenave e Freire, observando o sujeito para quem se fala, deslocando o foco dos meios às audiências. Antônio Heberlê (2014, p.19), por exemplo, propõe pensar a interação que a comunicação proporciona, sendo a comunicação para o desenvolvimento "uma esfera original 
de fluxos de informação que se estabelecem com o fim de promover e agilizar o processo de conhecimento e a sua apropriação pela sociedade, com a finalidade de transformar e melhorar as condições de vida dos sujeitos". Ao comunicador, cabe, conforme Heberlê trabalhar para a identificação de problemas por meio da interação comunicacional.

O contexto contemporâneo é de permanente revisão também sobre as concepções de desenvolvimento, que buscam não mais relacionar o processo exclusivamente ao crescimento econômico e reconhecer outras dimensões - social, ambiental, política, cultural - que importam no desenvolvimento das sociedades, bem como criar modos de aferi-las por meio de indicadores. Neste sentido, Amartya Sen publica, em 2000, o livro Desenvolvimento como liberdade. Apesar da obra representar uma ruptura com teorias do desenvolvimento anteriores, não constitui nenhuma surpresa. Diversos economistas, entre eles o próprio Sen, no final do século XX já discutiam a necessidade de ampliação do conceito e apresentavam diversos entendimentos. Amartya Sen, por exemplo, juntamente com MahbubulHaq, criou em 1993 o Índice de Desenvolvimento Humano, oIDH, que desdeentãoé utilizado pela ONU em seu relatório anual. A criação do IDH, assim como ocorreu posteriormente com a obra Desenvolvimento como Liberdade, foi um marco nas questões do desenvolvimento por incorporar indicadores como educação e longevidade, em vez de medir o desenvolvimento de um país apenas por seu PIB.

\section{Desenvolvimento como liberdade e o jornalismo}

Nas teorias tradicionais do desenvolvimento, como visto anteriormente, os fatores observados estavam especialmente relacionados ao crescimento econômico, vistos por meio da industrialização, da acumulação de capital, da mobilização de mão de obra, entre outros. Apesar de Sen (2010) apontar a limitação dessas concepções de desenvolvimento, destaca que ela não deve ser invalidada, mas sim ampliada. As questões do desenvolvimento devem ir além das puramente econômicas, como a análise baseada no Produto Interno Bruto (PIB) per capita, pois essa não abrange as condições de vida das pessoas. Essa reflexão denota um processo humanizador do conceito de desenvolvimento, que ultrapassa a análise baseada na riqueza. O próprio Sen (2010) compara a perspectiva do desenvolvimento como liberdade com a preocupação com a qualidade de vida das pessoas.

Conceituar o desenvolvimento como liberdade, na teoria de Sen (2010), é compreender que esse processo é multifacetado, ao contrário do que apontam muitos pesquisadores, os quais analisam apenas a variável da renda. Para Sen (2010), o desenvolvimento deve estar relacionado essencialmente à melhoria 
da qualidade de vida das pessoas por meio do fortalecimento da liberdade dos indivíduos.

Para que haja desenvolvimento, na concepção de Sen, é preciso que os indivíduos tenham oportunidades sociais adequadas e, assim, possam efetivamente mudar seus destinos e ajudar uns aos outros. A ligação entre o desenvolvimento e a liberdade individual das pessoas não se trata apenas de uma relação constitutiva. De acordo com Sen (2010), as oportunidades econômicas, as liberdades políticas, os poderes sociais e condições como boa saúde, educação básica e incentivo, influenciam as pessoas a realizarem algo positivamente. "As disposições institucionais que proporcionam essas oportunidades são ainda influenciadas pelo exercício das liberdades das pessoas, mediante a liberdade para participar da escolha social e da tomada de decisões públicas" (Sen, 2010, p.18).

As liberdades, sejam elas substantivas ou instrumentais, são o principal fim e o principal meio para o desenvolvimento, respectivamente, pois consistem em condições capacitadoras que permitem tanto o seu funcionamento, como também o da saúde, educação, entre outros. Nesse sentido, Sen (2010) defende que os indivíduos são os principais agentes do desenvolvimento. É essa capacitação individual que, para o autor, possibilita um conjunto de funcionamentos, sejam eles os mais simples, como comer, falar e pensar.

É importante compreender o que o autor chama de liberdades instrumentais e liberdades substantivas. A primeira consiste no meio, ou meios, para atingir o fim, ou seja, o desenvolvimento. São as liberdades instrumentais que levam o indivíduo ao aumento de sua liberdade total, ou, suas liberdades substantivas que, por sua vez, enriquecem a vida humana não apenas por meio do crescimento econômico, mas também com as escolhas individuais e livres.

Nessa pesquisa, além da compreensão do desenvolvimento como liberdade, interessa observar os desdobramentos das liberdades instrumentais. Sen (2010) apresenta cinco liberdades instrumentais. São elas: liberdades políticas, facilidades econômicas, oportunidades sociais, garantias de transparência e segurança protetora. Destaca-se a possibilidade e, por vezes, a necessidade desses grupos funcionarem de forma complementar. Segundo o autor, as liberdades contribuem para a capacidade geral de a pessoa viver livremente.

De acordo com Sen (2010), a abordagem do desenvolvimento não pode se concentrar nas mãos dos detentores do poder e destaca a necessidade da participação popular. Transferindo a ideia para o campo do jornalismo, se teria uma prática não concentrada em grandes grupos de comunicação e com a participação do seu público, seja na definição das pautas e da forma 
de abordagem dos temas, na presença como fonte, com direito de voz, numa concepção dos sujeitos como agentes ativos na produção e não só na recepção.

Observa-se que a prática jornalística seja nos veículos hegemônicos, seja na mídia alternativa ou independente, busca se legitimar por meio de um discurso de defesa do interesse público. Um discurso que, portanto, atravessa as diferentes categorias e concepções de jornalismo. McQuail (2012, p.208), na tentativa de explicar o que é o interesse público para o jornalismo, afirma que para os jornalistas o que define se uma pauta "vale a pena" é a consequência do seu consumo para a audiência, ou seja, quais fatos irão influenciar a vida das pessoas, o que a sociedade precisa saber. Nesse sentido, na prática jornalística, o interesse público seria sinalizado pela repercussão de uma informação: os fatos que ela provocaria e os comentários que suscitaria.

O campo do interesse público, portanto, é político, e também teórico, assim como o campo da função social do jornalismo. Reginatto (2016) mapeou as funções do jornalismo, segundo a teoria, e fez aproximações entre as considerações de diferentes autores. Entre as finalidades do jornalismo identificadas pela autora, são recorrentes: a contribuição do jornalismo com a democracia, a responsabilidade em informar, a formação da opinião pública, investigar e estimular o engajamento e mobilizar a participação cívica na vida pública.

Bucci (2000, p.49), por sua vez, define a função social do jornalismo como a de fortalecimento da democracia. Por isso o jornalismo "deve" ser um "fator de educação permanente do público" e acrescenta ainda que o público precisa ter o direito de conhecer os métodos e processos de produção e edição da notícia e, assim, ter conhecimento dos atravessamentos na produção.

A aproximação desse entendimento do jornalismo como tendo uma função social e sendo de interesse público com a concepção de Sen (2010), de um desenvolvimento como liberdade, é possível. A visão dos sujeitos como agentes ativos de mudanças e não apenas como receptores passivos, como sugerem os estudos de comunicação contemporâneos, é encontrada também nas considerações de Sen (2010) sobre o desenvolvimento visto como liberdade. Para o autor, o desenvolvimento é um processo integrado de expansão das liberdades individuais, ocorre quando há liberdades aos indivíduos.

Tanto a liberdade, quanto a própria ação das pessoas, para Sen (2010), está vinculada ao estímulo e incentivo dessas liberdades como desenvolvimento. Entende-se, aqui, que a promoção das liberdades e esses incentivos podem vir, entre outros meios, pelo acesso e apropriação da informação propagada pela mídia, que leva à geração de conhecimento. Como afirma o próprio 
Sen (2010, p.377), diversas instituições sociais contribuem para o processo de desenvolvimento por meio de seus efeitos e garantia das liberdades individuais: "ligadas à operação de mercados, a administrações, legislaturas, partidos políticos, organizações não governamentais, poder judiciário, mídia e comunidade em geral".

Compreende-se que o jornalismo, potencialmente, no exercício de sua função social, pode promover as liberdades instrumentais bem como contribuir para a não privação das liberdades apontadas também por Sen. Entendese, de acordo com o exposto, que a informação é um fator potencializador para a expansão das liberdades instrumentais e, consequentemente, para o desenvolvimento. Se, como afirma Sen (2010), o desenvolvimento se dá a partir da garantia de liberdades diversas, como, por exemplo, a garantia de participação política e social, a possibilidade de consumo (de informação, por exemplo), as oportunidades sociais (como educação, saúde, segurança social) e a garantia de transparência pelas diversas esferas, cabe questionar como a sociedade toma conhecimento de todos os direitos, deveres e serviços disponíveis. Esse conhecimento pode se dar principalmente por meio da mídia e, nela, do jornalismo, dada sua força e penetração na sociedade contemporânea.

\section{O circuito da cultura como protocolo teórico metodológico}

Toma-se como conceito de cultura a proposta de Williams (1989), para quem cultura é a maneira como se vive e os sentidos atribuídos a esse modo de viver. Hall (1997) complementa pensando as dimensões econômica e política da cultura na contemporaneidade, dada a expansão das produções das manifestações culturais, artísticas ou industriais, por meio das tecnologias da informação e da comunicação. A cultura tem caráter de "processo produtor de significações e não de mera circulação de informações" (Martín-Barbero, 2003, p.299).

No contexto contemporâneo, a comunicação midiática seria o principal meio de circulação da cultura e de seus significados na sociedade contemporânea, por meio de circuitos globais de trocas de informação, capital, investimento, produção de bens, produtos e ideias. É a natureza comunicativa da cultura, complementa Martín-Barbero (2003). A afirmação indica o diferencial de uma pesquisa em jornalismo a partir da abordagem cultural.

A práticajornalística, seus processos e seus produtos, pode ser considerada um fenômeno cultural, constituindo com a prática sócio-política da cultura (Felippi; Escosteguy, 2013). A relação entre cultura, comunicação e política é estabelecida por Martín-Barbero (2003): tanto a política, quanto a economia, na cultura, estão comprometidas com o que se produz na comunicação. Assim, 
estudar o jornalismo pelo viés da cultura possibilita que se preserve a dinâmica e as particularidades do processo jornalístico, sem isolar suas partes.

Destarte, os estudos culturais oferecem protocolos analíticos para a tomada do jornalismo na cultura. Entre os quais está o circuito da cultura, de Richard Johnson (2010), a partir do qual qualquer prática social pode ser analisada pelo viés da cultura. Contudo, o próprio autor sugere como objeto dos estudos culturais, a mídia e seus modos de consumo. Complementa afirmando que é preciso análises que revelem onde e de que forma as representações públicas agem para proporcionar à sociedade uma tendência emancipatória, bem como questiona esta pesquisa sobre a Agência Pública.

Nessa perspectiva, utiliza-se aqui, tanto como percurso metodológico, quanto como teoria, o modelo proposto por Johnson (2010), de circuito da cultura - O modelo busca observar o processo de produção de maneira integrada, perpassando tanto a própria produção, quanto o texto/produto, a leitura (consumo) e a cultura vivida que, oferecida pelo processo, devolve à produção essas relações sociais estabelecidas. Observa, também, as condições capitalistas nas quais os momentos desse processo estão submetidos. Constitui, assim, o entendimento de que o processo produtivo da cultura se trata de uma prática interdisciplinar.

O circuito é tomado para compreender as estratégias produtivas de uma agência de reportagens, no caso a Pública, na perspectiva da informação como fator para o desenvolvimento. Trata-se de uma estratégia produtiva diferenciada, com influência de condicionantes como a independência de anunciantes e financiadores, que resulta em um produto jornalístico pouco visto em outros veículos. É importante ainda ter claro a condição de agência de reportagens da Pública, ou seja, a disseminação do conteúdo produzido por ela para outros jornais, revistas ou portais, o que possibilita uma ampliação no número de leitores que entram em contato com as reportagens produzidas por ela.

Para fins de análise, se fez um recorte na reportagem Sob a fumaça, a dependência (Moriti Neto e Peres, 2015), publicada em outubro de 2015 pela Pública, que investigou a produção de tabaco, com foco nos agricultores familiares responsáveis por essa produção, suas condições de trabalho, de saúde e sua relação com as indústrias beneficiadoras do tabaco. A apuração se deu, parte em alguns municípios do Paraná, e outra na região do Vale do Rio Pardo, no Rio Grande do Sul, conhecida como maior produtora de fumo do país. Os dados foram coletados por meio de observação e entrevistas com repórteres e analisados à luz do circuito da cultura de Johnson (2010), como mostra a figura 1.

Destaca-se que para este estudo foram observadas as reportagens que estavam dispostas no site da Pública nos anos de 2015 e 2016, período de 
realização da pesquisa, buscando estabelecer recorrências e colher elementos para estruturar a análise da forma de produção da agência. Ver Figura 1.

- Figura 1 - Esquema de análise de dados

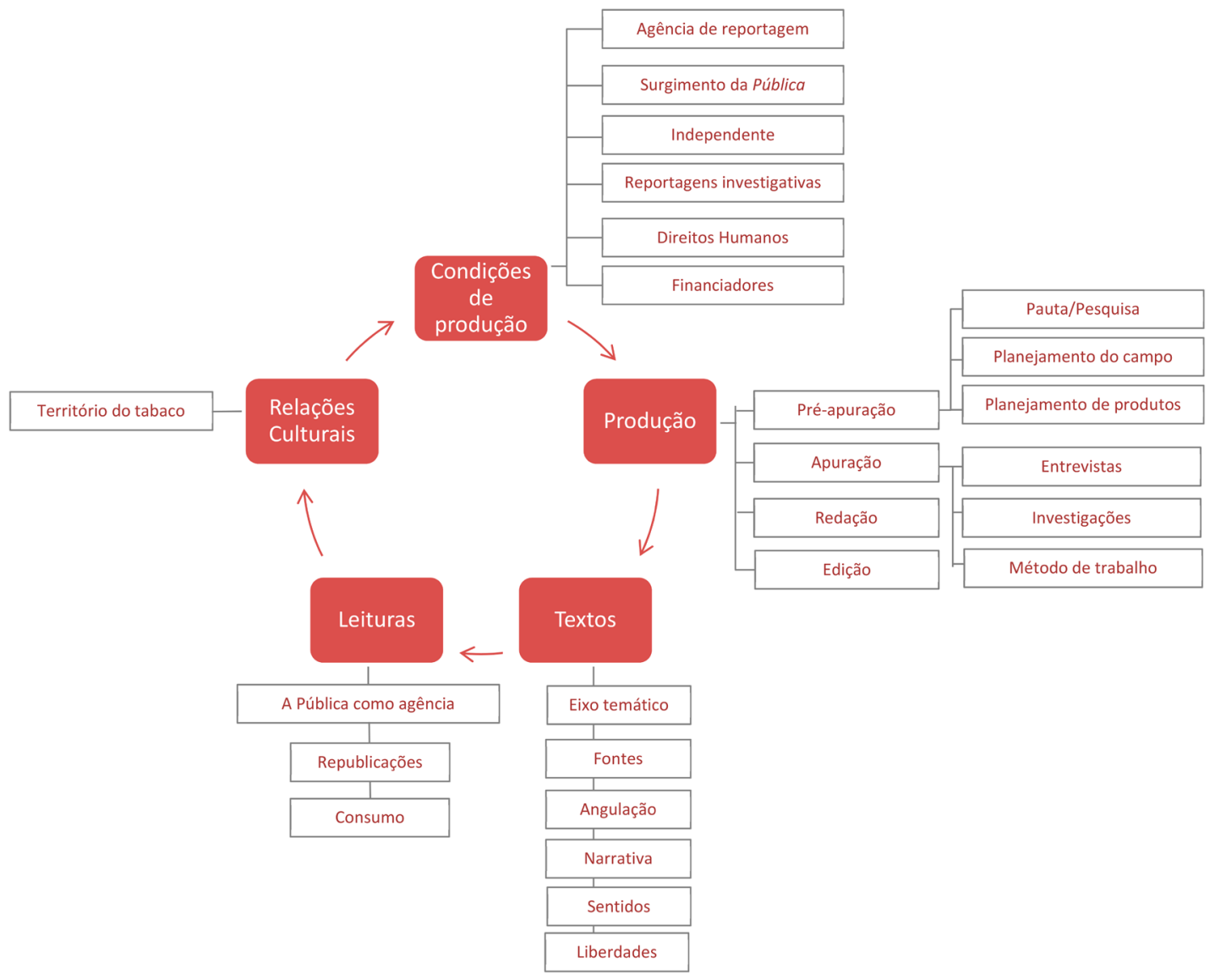

Fonte: as autoras

A Figura 1 apresenta categorias intermediárias em cada um dos momentos do circuito da cultura proposto por Johnson (2010), incluindo o momento das condições de produção. Apesar de "condições de produção"estar fora do circuito principal proposto pelo autor, aqui foi colocado como um momento específico do circuito por se entender que se trata de aspecto fundamental ao processo de produção cultural. Isso porque tais condições criam espaço para a produção, e também são influenciadas pelas relações culturais, sendo, portanto, crucial ao circuito.

A pesquisa é, portanto, de natureza qualitativa e percorre o circuito de Jonhson valendo-se de entrevistas com repórteres e editores da Agência Pública, análise documental do Estatuto da agência, da exposição sobre a mesma disposta em seu site oficial e da reportagem selecionada - sobre a produção de tabaco -, além de pesquisa bibliográfica. 


\section{A agência pública e a possibilidade de expansão das liberdades} individuais

A análise é apresentada por meio do percurso do circuito de Johnson (2010), indo das Relações sociais/culturas vividas a Textos, trazendo reflexões sobre as Leituras, muito embora este momento do circuito não tenha sido abordado empiricamente, dada a complexidade das pesquisas de recepção e os limites deste estudo. Os momentos são observados na sua inter-relação.

Deste modo, iniciando pelas Relações sociais, as mesmas dão conta das experiências sociais nas quais está inserido um processo produtivo cultural. As Relações sociais subsidiam a Produção e preparam para a Leitura (Johnson, 2010). Portanto, abordam-se, no artigo, aspectos do território onde foi construído a reportagem, dando conta das condições de vida e trabalho dos produtores do tabaco, atores da reportagem da Pública tomada para a análise do circuito produtivo e exame das possibilidades de expansão das liberdades.

O espaço do qual emerge a reportagem Sob a fumaça, a dependência pode ser circunscrito como sendo o território do tabaco no Brasil. Entende-se por território o espaço vivido, construído historicamente, na apropriação do mesmo e nas relações de poder. $\mathrm{O}$ território do tabaco corresponde a boa parte dos municípios dos estados do Sul do Brasil, onde se concentra quase a totalidade desta produção do país, bem como onde ficam as sedes das transnacionais que operam no beneficiamento e industrialização do tabaco. Este território é diverso, mas há características que predominam no que diz respeito à produção do tabaco, como a lavoura cultivada em propriedades pequenas, com mão de obra familiar envolvendo quase toda família, boa parte formada por descendentes de imigrantes europeus (alemães e italianos). Também predomina a produção realizada de forma integrada com as indústrias (com contratos de produção e comercialização) e o tabaco sendo o principal produto agrícola dessas propriedades rurais. Nesse território, são aproximadamente 150,1 mil famílias envolvidas no cultivo e 298,5 mil hectares de produção, resultando numa estimativa de ganho, na safra 2016/17 de R\$ 20.402,00, conforme a Associação dos Fumicultores do Brasil (Anuário Brasileiro do Tabaco, 2017). A produção do tabaco, cujo beneficiamento e industrialização gera o cigarro, é presente neste território desde o século XIX e a sociedade foi se organizando em torno dessa prática que tem influência direta na territorialidade do lugar. Na primeira metade do século $X X$, a produção de capital local foi dando lugar ao capital global, que, por sua vez, a impulsiona a ponto de transformar o Brasil no maior exportador do mundo e o segundo maior produtor de tabaco. Em que pese as campanhas antitabagistas, "nos últimos 15 anos, [...] a expansão da cultura [...] revela permanências e mudanças no modo de produção de tabaco 
com importantes reflexos nas dinâmicas de organização espacial, de relações socioeconômicas, e de usos do território" (Silveira, 2013, p.10).

O território manifesta contradições que evidenciam a subordinação técnica e econômica dos produtores de tabaco à exploração do trabalho familiar pelo capital agroindustrial. As "[...] empresas multinacionais materializam uma dada organização espacial que lhes seja interessante [...] ao processo de reprodução do capital" (Dornelles; Silveira, 2013, p. 35). As práticas territoriais interferem não apenas na economia e na articulação política dos municípios, mas nas relações culturais que se estabelecem, como por exemplo, o trabalho da imprensa. Esse reflete as contradições, sendo recorrentes as coberturas com angulação que manifestam positividade com relação à exploração do tabaco e defendem sua manutenção, em que pesem as campanhas mundiais pela diminuição do consumo do cigarro, o grau de dependência dos trabalhadores da cadeia em relação às empresas operadoras ou ainda as discussões sobre o uso da terra para a produção de alimentos.

Essa territorialidade incide sobre a Produção e os Textos, no circuito da cultura. Da mesma forma, interfere nas Condições de produção, que para efeito desta pesquisa foram elevadas à condição de um momento do circuito. Explorase,nesse momento, as condições que permitem que a Agência Pública opere na relação com sua proposta e a especificidade do negócio sem fins lucrativos e da ausência da publicidade como financiadora do jornalismo na referida pauta.

Como ponto de partida, o Estatuto da Agência Pública, de 29 de julho de 2011, capítulo IV, do Patrimônio, Art. 27, firma que

O patrimônio Social da associação será constituído de doações, patrocínios, resultados financeiros, de contratos, investimentos, legados, contribuições e auxílios de toda natureza dos associados e de pessoas físicas ou jurídicas, de direito público ou privado, que lhe venham a ser acrescidos, além de bens transferidos pelos associados ou terceiros e dos bens móveis ou imóveis que possui ou venha a possuir.

A independência jornalística, por meio de um regime sem fins lucrativos e com financiadores, parece ser uma característica muito cara à Pública. Já na sua apresentação, no site da Agência (Agência Pública, 2017), está a manifestação:

Nossa missão é produzir reportagens de fôlego pautadas pelo interesse público, sobre as grandes questões do país do ponto de vista da população - visando ao fortalecimento do direito à informação, à qualificação do debate democrática e à promoção dos direitos humanos. Funcionamos como uma agência: todas as nossas 
reportagens são livremente reproduzidas por uma rede de mais de 60 veículos sob a licença, creativecommons.

Nas palavras de uma diretora, "em todos os projetos e financiamentos da Pública, a regra é: os financiadores não olham o que vamos produzir, não temos nenhum compromisso editorial" (Viana, 2014, p. 1). A exigência está, muitas vezes, numa cláusula no contrato de parceria da agência com a instituição financiadora. Entre os financiadores estão fundações internacionais, como a Ford Foundatione a OakFoundation, e os financiadores individuais, por meio do crowdfunding, acessados através de chamadas públicas para determinadas pautas.

No caso da reportagem Sob a fumaça, a dependência, o financiamento veio da ONG Aliança de Combate ao Tabagismo (ACT), que financia ações antitabagistas no mundo. Silva Neto (2015b), que realizou a reportagem, atesta a não interferência da entidade financiadora na elaboração da pauta, tampouco na produção e redação. No entanto, cabe observar que, se de um lado não houve interferência da ACT quanto a produção e conteúdo da reportagem, de outro, cabe observar que se a Aliança de Controle ao Tabagismo propôs financiar essa pauta é porque havia interesse em fomentar o tema.

Evidenciou-se na pesquisa que a opção por recortar as investigações jornalísticas no tema transversal dos direitos humanos a diferencia da mídia hegemônica, vistoqueesseé um tema pouco tratado por ela eessencial ao debate democrático. Entre os eixos investigados estão "os impactos dos megaeventos esportivos; tortura e violência dos agentes do Estado; megainvestimentos na Amazônia; crise urbana; e empresas e violação dos direitos humanos" (Agência Pública, 2017).

Este aspecto das Condições de produção tem interferência direta no momento da Produção, na definição e elaboração da pauta. Assim como no momento anterior, a pauta também se coloca como um diferencial da estratégia da Pública, uma vez que os assuntos propostos para investigação estão condicionados ao tema dos direitos humanos.

A fala dos entrevistados para a pesquisa indica que são explorados fatos não trabalhados pelo jornalismo tradicional ou que não receberam o aprofundamento que a agência entende que deveriam ter: uma investigação qualificada, focada no interesse público, para qualificar o debate (Mota, 2016). As pautas estão condicionadas, portanto, à questão dos direitos humanos e os eixos temáticos apresentados, o que aproxima a perspectiva de trabalho da agência das liberdades instrumentais de Sen (2010). 
Cabe destaque a outros dois elementos da produção que marcam a estratégia produtiva da agência: o tipo de fontes entrevistadas (individuais e ligadas a movimentos sociais e sindicais) e, consequentemente, a angulação dada à reportagem na hora de se redigir o texto. Se é no planejamento de campo que se inicia a busca e o contato com as fontes, trata-se de um trabalho de seleção de pessoas a serem consultadas que, impreterivelmente, também contribuirão para certa angulação da reportagem.

Para a reportagem Sob a fumaça, a dependência, as fontes foram lideranças de instituições relacionadas à produção do tabaco, mas mais recorrentemente, agricultores e representantes de instituições que fazem frente a essa produção com ações alternativas, como uma ONG que fomenta produção orgânica, uma escola técnica agrícola com um ensino para o campo diferenciado do convencional, entre outras. Os repórteres fizeram contatos prévios às suas idas a campo com algumas fontes, mas boa parte foi levantada e contatada durante a apuração nas regiões visitadas (Silva Neto, 2015a). O propósito da pauta foi explorar as condições de trabalho e de vida dos agricultores relacionados à cadeia do tabaco no país. A reportagem foi apurada em dois momentos, em 2011 e em 2015, em duas regiões de produção, uma no Paraná e outro no Rio Grande do Sul, e por dois jornalistas freelancers que recorrentemente fazem trabalhos para a Pública, considerados jornalistas colaboradores.

Silva Neto (2015b) foi um dos jornalistas que fez a reportagem, e entrevistou integrantes de nove famílias produtoras de tabaco durante os cinco dias em que esteve fazendo a apuração numa das principais regiões produtoras de tabaco, no entorno do município de Santa Cruz do Sul, no Rio Grande do Sul. As entrevistas foram feitas nas propriedades das famílias, nas quais o jornalista chegava por intermédio ou indicação de alguma fonte ou instituição relacionada com a agricultura na região. Nas primeiras famílias, foi acompanhado de alguma representação sindical ou de lideranças de movimentos sociais, em outras, foi sozinho. As entrevistas constituíam em longas conversas, de acordo com o jornalista e, assim, foi possível observar, conforme o repórter, as contradições existentes entre as falas dos agricultores e do discurso dito oficial sobre a produção de tabaco.

Da Produção, chega-se aos Textos, momento em que se pode observar se há coerência entre o proposto pela Pública e o realizado, e assim estabelecer relações mais próximas com o propósito deste artigo e observar se a forma de operar da Pública potencialmente permitiria a realização das liberdades viabilizadoras do desenvolvimento.

A reportagem Sob a fumaça, a dependência foi publicada em outubro de 2015, sob a cartola de Meio Ambiente, e assinada pelos dois jornalistas que 
a realizam. Tem mais de 66 mil caracteres e explora as condições de produção dos agricultores do tabaco, dando voz majoritariamente aos mesmos. Reflexo do momento anterior, da Produção, as fontes e a angulação da pauta, que vai trazendo a realidade dos entrevistados, explorando as fragilidades do cultivo do tabaco em termos de riscos para a saúde, remuneração e relações com as empresas transnacionais do setor. Essas falas são entremeadas por relatos de agricultores que deixaram o cultivo do tabaco para se dedicarem a outras atividades menos danosas à saúde, como a produção de alimentos orgânicos, bem como a de autoridades do setor que fazem a defesa ou a crítica à produção do tabaco, com ênfase maior ao segundo grupo. A reportagem traz informações sobre a dependência que o produtor, e o território, possuem com a produção de fumo e a influência das relações trabalhistas estabelecidas entre produtor e indústrias de beneficiamento da planta.

"Lembro de olhar em volta quando era pequeno e só ver folhas de fumo. Não só na propriedade da minha família, mas nas que estão no entorno. Tinha uma sensação de opressão por isso", explica Anderson.O rapaz sabe do que fala. Viveu na pele os efeitos da prisão que é a cadeia do tabaco. Trabalhou, ainda criança, nas lavouras de fumo. Viu a família sofrer, inclusive fisicamente, e abrir mão de muito. Heitor, o pai de Anderson, hoje com 45 anos, foi um caso. Começou a plantar fumo aos 14 e passou 26 anos no cultivo. "Já não ia mais para a escola, nem concluí o ensino fundamental. Não dava para conciliar. O tabaco desgasta muito e eu tinha que ajudar meus pais", recorda (Peres; Silva Neto, 2015).

A presença desses aspectos em Textos está já no título da reportagem. A linha de apoio evidencia mais a abordagem. "Não são apenas os fumantes que estão atrelados a um hábito do qual é difícil se livrar. O Brasil, líder global na exportação de tabaco, oculta sob os dados econômicos um quadro social de efeitos devastadores". E o conteúdo, reforça a visão crítica sobre esta produção, apontando para uma certa abordagem do tema condizente com a pauta e com os propósitos da Pública.

"O principal problema é que o agricultor não tem chance de comercializar o produto com o preço que deveria comercializar", constata Vilmar Sergiki, presidente do Sindicato dos Trabalhadores Rurais de Palmeira, na região central do Paraná.E Santa Cruz é o berço de tudo. A casa das fumageiras, o que faz entender tanto medo e tamanha sensação de vigilância. Mesmo nesse contexto, duas pessoas, além de Sighard, finalmente se candidatam a falar. Dois agricultores. Origens e idades diferentes. Em comum, o fumo que atravessou suas vidas (Peres; Silva Neto, 2015). 
Em Condições de produção e em Produção já se observou que a Públicaouve primeiro a fonte individual relacionada ao acontecimento para depois buscar respostas junto outras fontes institucionais, o que se confirmou na reportagem analisada. Silva Neto (2015b) diz que a prioridade foi ouvir os agricultores e conhecer a sua realidade, ainda que tenha mencionado, no planejamento de campo, diversas outras fontes. A inversão de prioridade em relação à prática do jornalismo convencional - que se vale mais de fontes oficiais - por determinado grupo de fontes, explicita uma particularidade da estratégia produtiva da Pública, que se articula aos seus princípios.

Lídia é a prova disso. Em 2009, depois de muitos anos de peregrinação hospitalar, finalmente médicos começaram a descobrir de que se tratava o caso. E ela virou o ponto de partida de uma pesquisa do Núcleo de Estudos em Saúde Coletiva da Universidade Federal do Paraná (UFPR). Após seis anos, os resultados preliminares do trabalho, cedidos à Pública, dão conta do problema. A avaliação médica e toxicológica de 46 fumicultores da região central do Paraná mostra que em 20 deles há sinais claros de relação entre intoxicação crônica e o trabalho na roça (Peres; Silva Neto, 2015).

Ainda que o momento Leituras não fosse objeto da pesquisa, faz-se necessário apontar algumas questões relativas ao consumo da reportagem. O propósito de uma agência é a multiplicação do conteúdo produzido. $O$ conteúdo da Pública tem entrada maior em mídias alternativas, como na Agência Nacional das Favelas, na Agência Patrícia Galvão, na Catraca Livre, entre outras, muito embora haja, entre os 54 republicadores indicados no site da Pública, veículos como Folha de São Paulo e El País Brasil. O conteúdo da Pública é acessado também diretamente no site pelo leitor final. Tem uma média de 100 mil acessos ao mês e a reportagem sobre o tabaco recebeu 6 mil cliques $^{1} \mathrm{e}$ em torno de 40 comentários diretamente na página. Por ser disponibilizado de forma gratuita e online, o conteúdo produzido pela Pública tem potencialmente grande abrangência, muito embora, nas entrevistas, os jornalistas demonstrem ter percepções sobre o leitor final, porém não têm claro seu perfil, apontando talvez para o que seja uma fragilidade do processo produtivo que não faz aferição da recepção de seu conteúdo.

\section{As liberdades individuais e a estratégia produtiva da Pública}

O desenvolvimento como liberdade perpassa a garantia das (1) liberdades instrumentais para, então, se ter a (2) liberdade substantiva que consiste no

1 Até o fechamento desta pesquisa, no início de 2017. 
próprio desenvolvimento. Apesar da possibilidade de verificar individualmente cada uma das liberdades instrumentais, Sen (2010, p.25) destaca que elas atuam de maneira a se complementar. "Na visão do desenvolvimento como liberdade, as liberdades instrumentais ligam-se umas às outras e contribuem com o aumento da liberdade humana em geral".

Sendo assim, ordenando as liberdades instrumentais para efeito de análise, as (a) facilidades econômicas, por exemplo, não apenas elevam a renda e possibilitam o consumo, como também permitem ao Estado financiar a segurança protetora e as oportunidades sociais. A (b) liberdade das oportunidades sociais, deste modo, diz respeito às condições que proporcionam que os indivíduos vivam melhor. A garantia dessa liberdade seria importante tanto para a vida privada, quanto para uma participação mais efetiva dos cidadãos nas atividades políticas e econômicas. Temas centrais na reportagem estudada, a saúde e as condições de trabalho do produtor de tabaco são assuntos que, num tratamento dado aos assuntos como a Pública realizou na reportagem estudada, informam o leitor e geram um conhecimento que $o$ capacita a expandir as oportunidades sociais. Oportunizar o acesso à informação é fundamental, pois garante que a sociedade tenha conhecimento não só sobre o que ocorre, mas também sobre serviços disponíveis, por exemplo. Observase na Pública um movimento que é informacional, mas também político. Ao possibilitar o consumo de certos produtos, com acesso gratuito para o público final e para a mídia em geral, via republicação, as pessoas passam a ter condição de poder de decisão, ou seja, uma maior liberdade e potencialidade de facilidades econômicas. De acordo com Sen (2010, p.59), as facilidades econômicas "são as oportunidades que os indivíduos têm para utilizar recursos econômicos com propósitos de consumo, produção ou troca".

Aproximação da estratégia produtiva da agência com essa liberdade se dá pela oportunidade de consumo de um produto jornalístico, que é informacional, de forma gratuita e por meio de diversas mídias e plataformas, uma vez que a Pública opera com a republicação de seu conteúdo. Na visão de Sen (2010, p.60), nas interações sociais, as relações entre os sujeitos se dão com base "em alguma suposição sobre o que lhes está sendo oferecido e o que podem esperar obter". A (c) liberdade de garantias de transparência diz respeito justamente a isso, à necessidade de sinceridade pela sociedade, com uma garantia de dessegredo e clareza. As garantias de transparência são observadas na reportagem Sob a fumaça, a dependência, nas informações plurais oferecidas ao leitor no texto, com o uso de fontes que não são as ditas oficiais e na angulação dada à reportagem. Essa liberdade instrumental é aqui 
contemplada, também, visto que a reportagem sobre a produção de tabaco investiga a relação econômica que se estabelece entre produtores e indústrias, que evidencia um desequilíbrio entre as partes, garantindo uma transparência de informação. Mudanças materiais, ou não, podem afetar adversamente a vida das pessoas e, assim, as colocar sob uma vulnerabilidade social, uma grande privação (Sen, 2010). A (d) segurança protetora dá conta de uma rede de segurança social. Na reportagem sobre o tabaco no sul do Brasil observa-se a possibilidade de expansão dessa liberdade instrumental dada a liberdade que a Pública oportuniza às fontes individuais: de ter um espaço para falar sobre sua situação de trabalho, nesse caso, enquanto produtores de fumo. Por fim, as (e) liberdades políticas, também perpassam todo o circuito produtivo da Pública. Esta liberdade instrumental refere-se à possibilidade que as pessoas têm de escolher quem deve governar e com base em quais princípios, e, dá conta da possibilidade de fiscalização e crítica às autoridades, à liberdade de expressão e de escolha. Inclui também os poderes políticos associados às democracias, como as oportunidades de diálogo. Observa-se que o trabalho da Pública tem condições para potencializar essa liberdade, diante de seu modo de operação analisado, por exemplo, fornecendo subsídios para a participação política e social dos indivíduos e na medida em que ouve as pessoas, suas reinvindicações.

\section{Considerações finais}

A partir desta pesquisa entende-se que a Pública, enquanto agência de reportagens que se propõe defender os direitos humanos e apresentar aos seus leitores reportagens investigativas que deem conta das fragilidades da realidade social brasileira, está possibilitando a expansão das liberdades instrumentais aos seus leitores. Há coerência entre os princípios e a prática da Pública e sua estratégia produtiva se mostra como uma possibilidade interessante de jornalismo como promotor do desenvolvimento.

Muito embora esta pesquisa não tivesse como objetivo avaliar o momento da recepção da reportagem, mas sim se os materiais produzidos pela Pública a partir de certas condições, carregavam potencial para estabelecer uma relação possível entre o jornalismo e o desenvolvimento, ao expor as diversas situações de risco aos direitos humanos presentes na realidade nacional e cobrar que algo seja feito. A estratégia produtiva do jornalismo da agência corrobora para a remoção das principais privações de liberdades.

Nesse sentido, uma perspectiva crítica, dificultada pela mídia hegemônica, dada sua natureza comercial, é encontrada em modelos de produção jornalística como o da Pública. Pôde-se observar que se trata de uma abordagem carente 
de estudos, principalmente quando se constata a importância do trabalho da mídia dentro de um processo de desenvolvimento.

\section{REFERÊNCIAS}

ANUÁRIO BRASILEIRO DO TABACO 2017. Santa Cruz do Sul. Editora Gazeta, 2017. Disponível em: http://www.editoragazeta.com.br/wp-content/ uploads/2016/12/PDF-TABACO_2016.pdf. Acesso em: 12 abr. 2017.

AGÊNCIA PÚBLICA. Sobre. 2017. Disponível em: http://PUBLICA.org/quemsomos/\#sobre. Acesso em: 10 abr. 2017.

. Estatuto do Centro de Jornalismo Investigativo. 2011. Disponível em: http://PUBLICA.org/quem-somos/\#sobre. Acesso em: 10 abr. 2017.

BORDENAVE, Juan E. Diaz. O que é comunicação rural? São Paulo: Brasiliense, 1985.

- Novas perspectivas na capacitação em comunicação para o desenvolvimento rural. Rio de Janeiro: INCA, 1974.

BUCCl, Eugênio. Sobre ética e imprensa. São Paulo: Companhia das Letras, 2000.

DORNELLES, Mizael; SILVEIRA, Rogério Leandro Lima da. A produção de tabaco no sul do Brasil: um olhar geográfico sobre a sua dinâmica produtiva e organização territorial. In: SILVEIRA, Rogério Leandro Lima da (Org.). Tabaco, sociedade e território: relações e contradições no sul do Brasil. Santa Cruz do Sul: Edunisc, 2013. p. 23-40.

FELIPPI, Ângela C.T., ESCOSTEGUY, Ana Carolina. Jornalismo e estudos culturais: a contribuiçãodeJesús Martín-Barbero.Rumores, v.7,n.14,p.8-27,2013.Disponível em: http://www.revistas.usp.br/Rumores/article/viewFile/69433/72013. Acesso em: 15 out. 2015. https://doi.org/10.11606/issn.1982-677X.rum.2013.69427.

FREIRE, Paulo. Extensão ou comunicação? São Paulo: Paz e Terra, 2011.

HEBERLÊ, Antonio. O papel dos Relações Públicas na comunicação para o desenvolvimento. In: GONÇALVES, Gisela; FELIPPI, Ângela. Comunicação, desenvolvimento e sustentabilidade. Covilhã: LabCom, 2014. p. 9-20.

HUNT, E. K.; SHERMAN, Howard J. História do pensamento econômico. Petrópolis: Vozes, 2010. 
JOHNSON, Richard. O que é, afinal, os Estudos culturais? In: JOHNSON, Richard; ESCOSTEGUY, Ana Carolina; SCHULMSN, Norma. O que é, afinal, Estudos culturais? Belo Horizonte: Autêntica Editora, 2010.

LERNER, Daniel; SCHRAMM, Wilbur. Comunicação e mudança nos países em desenvolvimento. São Paulo: Melhoramentos, 1973.

MARTÍN-BARBERO, Jesús. Dos meios às mediações. Rio de Janeiro: UFRJ, 2003.

MCQUAIL, Denis.Atuação da mídia:comunicação de massa e interesse público. Porto Alegre: Penso, 2012.

MELO. José Marques de. Subdesenvolvimento, urbanização e comunicação. Petrópolis: Editora Vozes, 1977.

MOTA, Jessica. O trabalho jornalístico na Agência Pública. 2016. Arquivo de áudio digital (22min).

PERES, João; SILVA NETO, Moriti. Sob a fumaça, a dependência. Agência Pública. 26 out. 2015. Disponível em: http://apublica.org/2015/10/sob-a-fumaca-adependencia/. Acesso em: 26 fev. 2017.

REGINATTO, Gisele Dotto. As finalidades do jornalismo: o que dizem os veículos, jornalistas e leitores. 2016. 260p. Tese (doutorado). Universidade Federal do Rio Grande do Sul, 2016.

SEN, Amartya. Desenvolvimento como liberdade. São Paulo: Companhia de Bolso, 2010.

SILVA NETO, Moriti. A construção da pauta e o planejamento da apuração em campo para a reportagem Fumo, Fogo e Fumaça. Entrevistadora: V.C. Oliveira, 2015a. Arquivo de áudio digital (1h20min). Entrevista concedida à pesquisa A estratégia produtiva de uma agência de reportagens na perspectiva da informação como fator para o desenvolvimento.

A apuração de campo para a reportagem Fumo, Fogo e Fumaça. Entrevistadora:V.C. Oliveira, 2015b. Arquivo deáudio digital (1h14min). Entrevista concedida à pesquisa $A$ estratégia produtiva de uma agência de reportagens na perspectiva da informação como fator para o desenvolvimento.

SILVEIRA, Rogério Leandro Lima da (Org.).Tabaco, sociedade e território: relações e contradições no sul do Brasil. Santa Cruz do Sul: Edunisc, 2013.

VIANA, Natália. 2014. In: MALIN, Mauro. Agência Pública luta pelo bom jornalismo. Disponível em: http://observatoriodaimprensa.com.br/imprensa-em-questao/_ ed783_agencia_publica_luta_pelo_bom_jornalismo_. Acesso em: 11 set. 2016.

WILLIAMS, Raymond. Culture is ordinary. In: WILLIAMS, Raymond. Resources of hope: Culture, Democracy, Socialism. London: Verso, 1989, p. 3-14. 
Recebido em: 31/5/2017

Aceito em: 26/9/2017

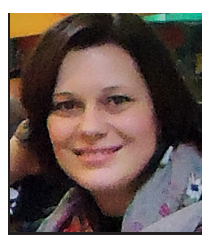

Dados das autoras:

Ângela Cristina Trevisan Felippi | angelafe@unisc.br

Universidade de Santa Cruz do Sul (UNISC).

Docente da Universidade de Santa Cruz do Sul. Doutora em Comunicação Social pela Pontifícia

Universidade Católica do Rio Grande do Sul. Programa de Pós-Graduação em Desenvolvimento Regional (PPGDR), Universidade de Santa Cruz do Sul (UNISC).

Endereço da autora:

PPGDR - bloco 10, Campus da UNISC, Avenida Independência, 2293, Bairro Universitário, Santa Cruz do Sul, (RS) - Brasil.

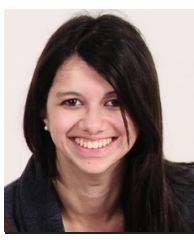

Vanessa Costa de Oliveira| nessa.costa.oliveira@gmail.com

Universidade de Santa Cruz do Sul (UNISC).

Doutoranda e Mestra em Desenvolvimento Regional pela Universidade de Santa Cruz do Sul (UNISC).

Endereço da autora:

R. Jesus Gil, 2293 - Universitário

96815-900 - Santa Cruz do Sul (RS) - Brasil. 